\title{
Effectiveness of Revised Nursing Care Standard Operative Procedures on Knowledge and Practice Regarding Essential Newborn Care
}

\author{
Ms. Devangi Sharma ${ }^{1}$, Mr. Nirmal Raj ${ }^{2}$, Mr. Rajesh Joseph ${ }^{3}$ \\ ${ }^{l}$ Final Year M.Sc Nursing (Child health nursing) student studying in Sumandeep Nursing College, Sumandeep \\ Vidayapeeth University \\ ${ }^{2}$ Guide during this research work \\ ${ }^{3}$ Co-guide during the research work Sumandeep Vidayapeeth University Sumandeep Nursing College
}

\begin{abstract}
Neonatal Mortality rate of India is found to be 30 deaths per 1,000 live births in 2015 which accounts for 38 percent of global neonatal deaths. The major three causes which include the neonatal/maternal infection, intra-partum conditions and premature births of newborn deaths account for 88\%.Quantitative evaluatory approach with quasi experimental non randomized control group design including 117 nursing students (E-59 \& C-58) were selected as samples using purposive sampling technique and a questionnaire to assess the knowledge and checklist for assessing the practice were administered. The pre-test mean percentage score of knowledge and practice was $38.56 \%$ and $44.1 \%$ and that in the experimental group knowledge and practice score was $36.86 \%$ and $40.80 \%$. The teaching session and the simulated training regarding revised standard operative procedure were effective as there is a significant difference in the pre-test and post-test knowledge and practice score among the experimental group.
\end{abstract}

Key Words: Standard Operative Procedures, Essential Newborn care, Revised Nursing Care

\section{Introduction}

Essential newborn care is a comprehensive strategy which is designed to improve the health of a newborn through interventions before conception, during pregnancy, at and soon after birth, and also in the postnatal period. Newborn morbidity and mortality contributes significantly to the infant mortality and underfive mortality rates in most developing countries including India. About two-thirds of all infant deaths and 38\% of all under-five deaths occur during the neonatal period, resulting in about 4 million neonatal deaths globally per year. Babies delivered at home may have a greater risk of being exposed to unhealthy care practices, compared to babies delivered in health facilities. Neonatal Mortality rate of India is found to be 30 deaths per 1,000 live births in 2015 which accounts for 38 percent of global neonatal deaths. Of every four children who die in one is a newborn. The major three causes which include the neonatal/maternal infection, intra-partum conditions and premature births of newborn deaths account for $88 \%$ of newborn deaths.

\section{Aims \& Objectives of the Study}

1. Assess the knowledge and practice regarding essential newborn care among nursing students by pre test.

2. Plan and administer revised nursing care SOP on essential newborn care to experimental group.

3. Evaluate the effectiveness of the revised nursing care, standard operative procedures on essential new born care in experimental group by post test.

4. Find out the correlation between the pre-test knowledge and practice regarding the essential newborn care among the selected nursing students.

$\mathbf{H}_{\mathbf{1}}$ - There will be the significance difference between the mean pre-test and post-test knowledge and practice score in the experimental group.

\section{ASSUMPTION}

1. The selected nursing students will not have adequate knowledge regarding standard operative procedures on essential newborn care.

2. The revised nursing care, standard operative procedures will improve the knowledge and practice of students. 


\section{Methods \& Materials}

Evaluative research approach with quasi experimental research design with non randomized control group was implemented among 117 Nursing Students (control group-58; experimental group-59) using purposive sampling technique. Selected nursing students were from $3^{\text {rd }}$ year B.Sc, $3^{\text {rd }}$ year GNM \& $1^{\text {st }}$ year PB.BSc studying in Sumandeep Nursing College. Tools used for data collection were: structured knowledge questionnaire for knowledge and checklist for practice.

\section{Findings}

The findings were analyzed and presented in table and diagrams in the following areas:

\section{Section I: Assessment of Knowledge Score In Both Experimental And Control Group For Both The Pre And Post Test}

Table: 1: Assessment of Knowledge Regarding Essential Newborn Care Pre-Test Experimental Group (Aspectwise)

\begin{tabular}{|c|l|c|c|c|c|}
\hline SNO & \multicolumn{1}{|c|}{ KNOWLEDGE ASPECTS } & $\begin{array}{c}\text { MAX. } \\
\text { SCORE }\end{array}$ & MEAN & MEAN\% & SD \\
\hline 1 & Knowledge on The Newborn & 03 & 1.23 & 41 & 0.23 \\
\hline 2 & Knowledge on The Breastfeeding & 03 & 1.35 & 45 & 0.21 \\
\hline 3 & Knowledge on The Care Of Newborn & 09 & 3.16 & 35.11 & 0.76 \\
\hline 4 & Knowledge on The Standard Operative Procedure & 04 & 1.25 & 31.25 & 0.35 \\
\hline 5 & Knowledge on The Newborn Assessment & 11 & 4.05 & 36.81 & 0.90 \\
\hline & Over All Knowledge Score & $\mathbf{3 0}$ & $\mathbf{1 1 . 0 6}$ & $\mathbf{3 6 . 8 6}$ & $\mathbf{2 . 4 6}$ \\
\hline
\end{tabular}

Above table and the column diagram reveals that the newborn aspect comprising of 3 items had a mean of 1.23 with a standard deviation of 0.3 and mean $\%$ of $41 \%$. Breastfeeding with 3 items had a mean of 1.35 with a standard deviation of 0.21 and mean $\%$ of $45 \%$. Care of newborn with 9 items had a mean of 3.16 with a standard deviation of 0.76 and mean $\%$ of $35.11 \%$.Standard operative procedure with 4 items had a mean of 1.25 with 0.35 standard deviation and a mean $\%$ of $31.25 \%$. Newborn Assessment with 11 items had a mean of 4.05 with 0.90 Standard deviation and a mean $\%$ of $36.81 \%$. Overall knowledge had 30 items and the mean was found to be 11.06 , SD 2.46 and mean $\%$ of $36.86 \%$.

Figure: 1

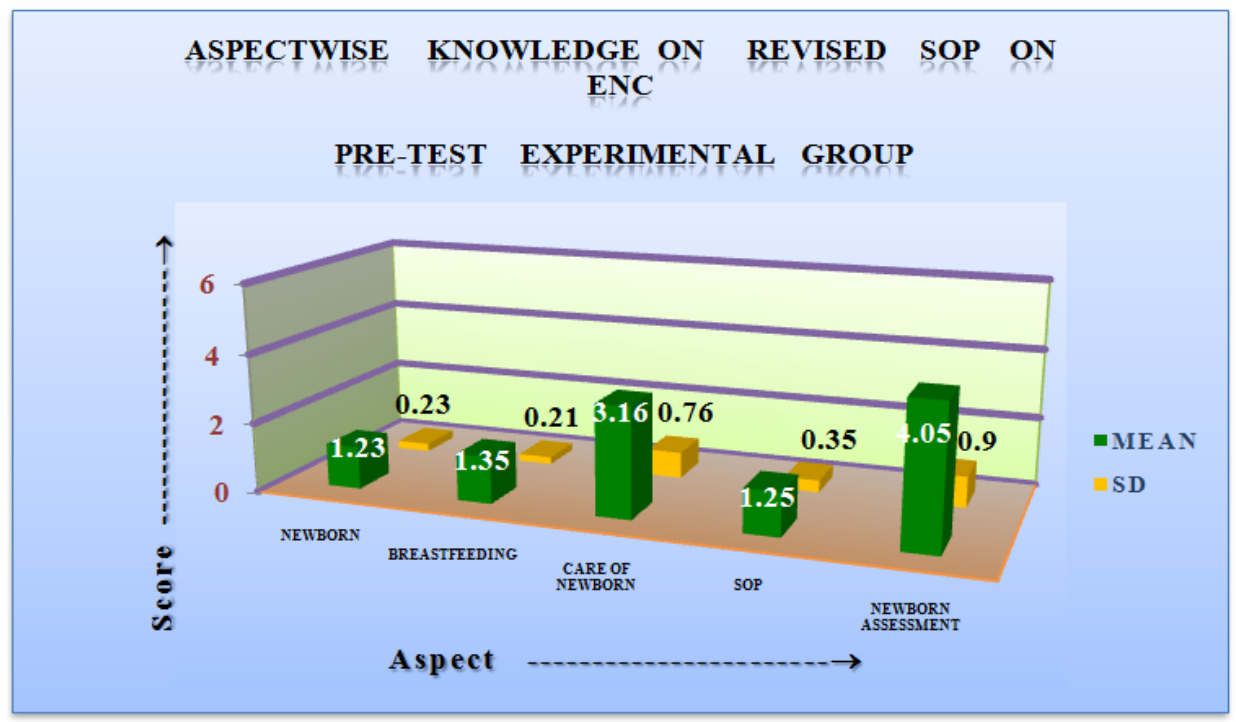


Table 2: Assessment of Knowledge Regarding Essential Newborn Care Post-Test Experimental Group (Aspectwise)

\begin{tabular}{|c|l|c|c|c|c|}
\hline SNO & \multicolumn{1}{|c|}{ KNOWLEDGE ASPECTS } & $\begin{array}{c}\text { MAX. } \\
\text { SCORE }\end{array}$ & MEAN & MEAN\% & SD \\
\hline 1 & Knowledge on The Newborn & 03 & 2.44 & 81.33 & 0.07 \\
\hline 2 & Knowledge on The Breastfeeding & 03 & 2.50 & 83.33 & 0.06 \\
\hline 3 & Knowledge on The Care Of Newborn & 09 & 7.89 & 87.66 & 0.14 \\
\hline 4 & $\begin{array}{l}\text { Knowledge on The Standard Operative } \\
\text { Procedure }\end{array}$ & 04 & 3.47 & 86.75 & 0.06 \\
\hline 5 & Knowledge on The Newborn Assessment & 11 & 9.44 & 85.81 & 0.02 \\
\hline & Over All Knowledge Score & $\mathbf{3 0}$ & $\mathbf{2 5 . 7 6}$ & $\mathbf{8 5 . 8 6}$ & $\mathbf{0 . 5 5}$ \\
\hline
\end{tabular}

Above table reveals that the newborn aspect comprising of 3 items had a mean of 2.44 with a standard deviation of 0.07 and mean \% of $81.33 \%$. Breastfeeding with 3 items had a mean of 2.50 with a standard deviation of 0.06 and mean\% of $83.33 \%$. Care of newborn with 9 items had a mean of 7.89 with a standard deviation of 0.14 and mean $\%$ of $87.66 \%$.Standard operative procedure with 4 items had a mean of 3.47 with 0.06 standard deviation and a mean\% of $86.75 \%$. Newborn Assessment with 11 items had a mean of 9.44 with 0.02 Standard deviation and a mean $\%$ of $85.81 \%$. Overall knowledge had 30 items and the mean was found to be 25.76 , SD 0.55 and mean $\%$ of $85.86 \%$.

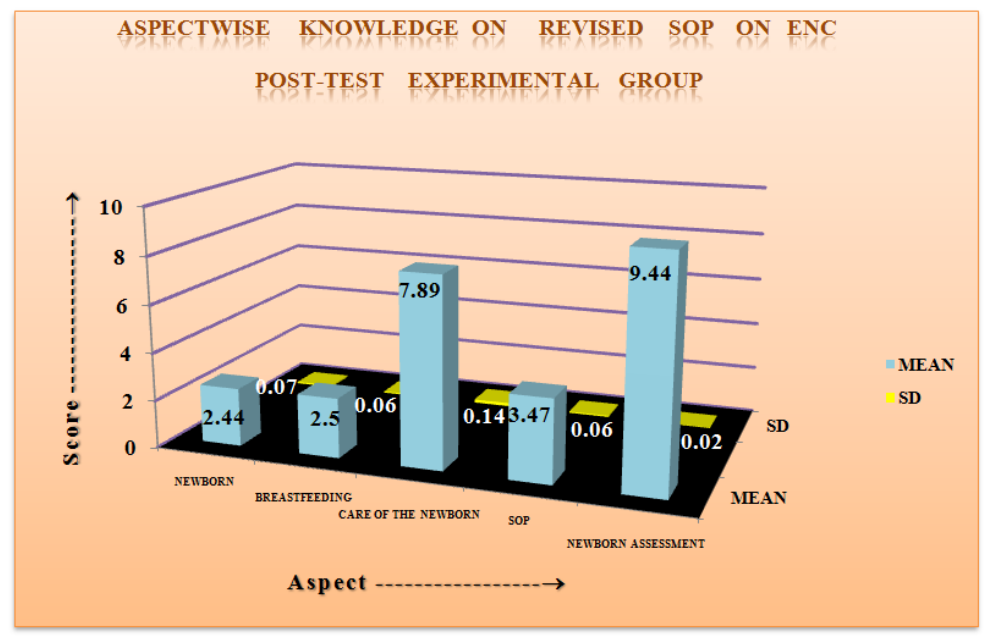

Figure: 2

Above column diagram reveals that the newborn aspect comprising of 3 items had a mean of 2.44 with a standard deviation of 0.07 . Breastfeeding with 3 items had a mean of 2.50 with a standard deviation of 0.06 . Care of newborn with 9 items had a mean of 7.89 with a standard deviation of 0.14 .Standard operative procedure with 4 items had a mean of 3.47 with 0.06 standard deviation . Newborn Assessment with 11 items had a mean of 9.44 with 0.02 Standard deviation.

Table : 3: Assessment Of Knowledge Regarding Essential Newborn Care Pre-Test Control Group

\begin{tabular}{|c|l|c|c|c|c|}
\hline (Aspectwise) & \multicolumn{1}{c|}{ MAX. } \\
SNO & \multicolumn{1}{|c|}{ KNOWLEDGE ASPECTS } & MEAN & MEAN\% & SD \\
\hline 1 & Knowledge on The Newborn & 03 & 1.32 & 44 & 0.22 \\
\hline 2 & Knowledge on The Breastfeeding & 03 & 1.18 & 39.33 & 0.23 \\
\hline 3 & Knowledge on The Care Of Newborn & 09 & 3.01 & 33.44 & 0.78 \\
\hline 4 & Knowledge on The Standard Operative Procedure & 04 & 1.41 & 35.25 & 0.34 \\
\hline 5 & Knowledge on The Newborn Assessment & 11 & 4.62 & 42 & 0.83 \\
\hline & Over All Knowledge Score & $\mathbf{3 0}$ & $\mathbf{1 1 . 5 6}$ & $\mathbf{3 8 . 5 6}$ & $\mathbf{2 . 4 2}$ \\
\hline
\end{tabular}


Figure: 3

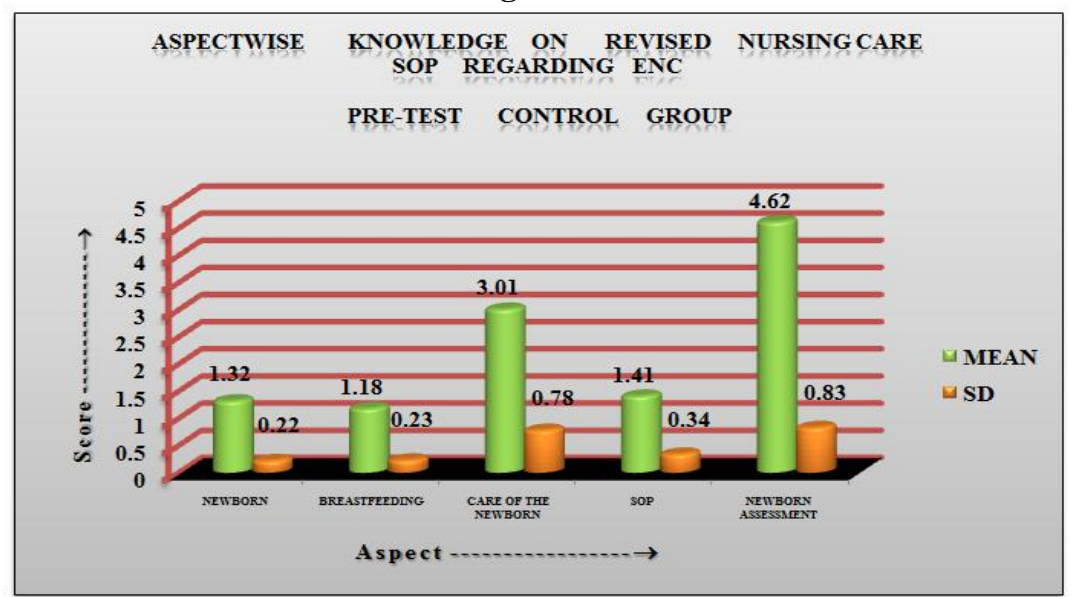

Above table and the column diagram reveals that the newborn aspect comprising of 3 items had a mean of 1.32 with a standard deviation of 0.22 and mean $\%$ of $44 \%$. Breastfeeding with 3 items had a mean of 1.18 with a standard deviation of 0.23 and mean of $39.33 \%$. Care of newborn with 9 items had a mean of 3.01 with a standard deviation of 0.78 and mean $\%$ of $33.44 \%$.Standard operative procedure with 4 items had a mean of 1.41 with 0.34 standard deviation and a mean $\%$ of $35.25 \%$. Newborn Assessment with 11 items had a mean of 4.62 with 0.83 Standard deviation and a mean $\%$ of $42 \%$. Overall knowledge had 30 items and the mean was found to be 11.56 , SD 2.42 and mean $\%$ of $38.56 \%$.

Table : 4 :Assessment of Knowledge Regarding Essential Newborn Care Post-Test Control Group (Aspectwise)

\begin{tabular}{|c|l|c|c|c|c|}
\hline SNO & \multicolumn{1}{|c|}{ KNOWLEDGE ASPECTS } & $\begin{array}{c}\text { MAX. } \\
\text { SCORE }\end{array}$ & MEAN & MEAN\% & SD \\
\hline 1 & Knowledge on The Newborn & 03 & 1.29 & 43 & 0.22 \\
\hline 2 & Knowledge on The Breastfeeding & 03 & 1.24 & 41.33 & 0.23 \\
\hline 3 & Knowledge on The Care Of Newborn & 09 & 3.15 & 35 & 0.76 \\
\hline 4 & $\begin{array}{l}\text { Knowledge on The Standard Operative } \\
\text { Procedure }\end{array}$ & 04 & 1.43 & 35.75 & 0.33 \\
\hline 5 & Knowledge on The Newborn Assessment & 11 & 4.60 & 41.81 & 0.84 \\
\hline & Over All Knowledge Score & $\mathbf{3 0}$ & $\mathbf{1 1 . 7 2}$ & $\mathbf{3 9 . 0 8}$ & $\mathbf{2 . 4 0}$ \\
\hline
\end{tabular}

Figure:4

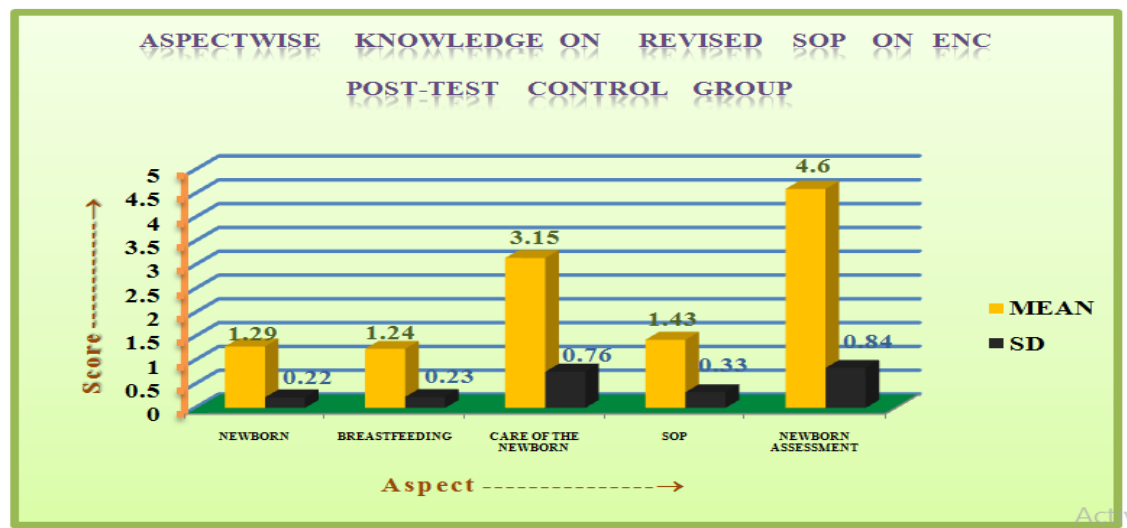

Above table and figure reveals that the newborn aspect comprising of 3 items had a mean of 1.29 with a standard deviation of 0.22 and mean $\%$ of $43 \%$. Breastfeeding with 3 items had a mean of 1.24 with a standard deviation of 0.23 and mean of $41.33 \%$. Care of newborn with 9 items had a mean of 3.15 with a standard deviation of 0.76 and mean $\%$ of $35 \%$.Standard operative procedure with 4 items had a mean of 1.43 with 0.33 standard deviation and a mean $\%$ of $35.75 \%$. Newborn Assessment with 11 items had a mean of 4.60 with 0.84 Standard deviation and a mean $\%$ of $41.81 \%$. Overall knowledge had 30 items and the mean was found to be 11.72, SD 2.40 and mean $\%$ of $39.08 \%$. 
Table: 5 Overall Distribution of Respondent To Knowledge Level In Pre-Test

\begin{tabular}{|l|c|c|}
\hline \multicolumn{1}{|c|}{ SCORE } & \multicolumn{2}{|c|}{ KNOWLEDE } \\
\hline & FREQUENCY & \% \\
\hline Poor & 45 & 38.46 \\
\hline Average & 71 & 60.69 \\
\hline Good & 1 & 0.85 \\
\hline
\end{tabular}

Figure: 5

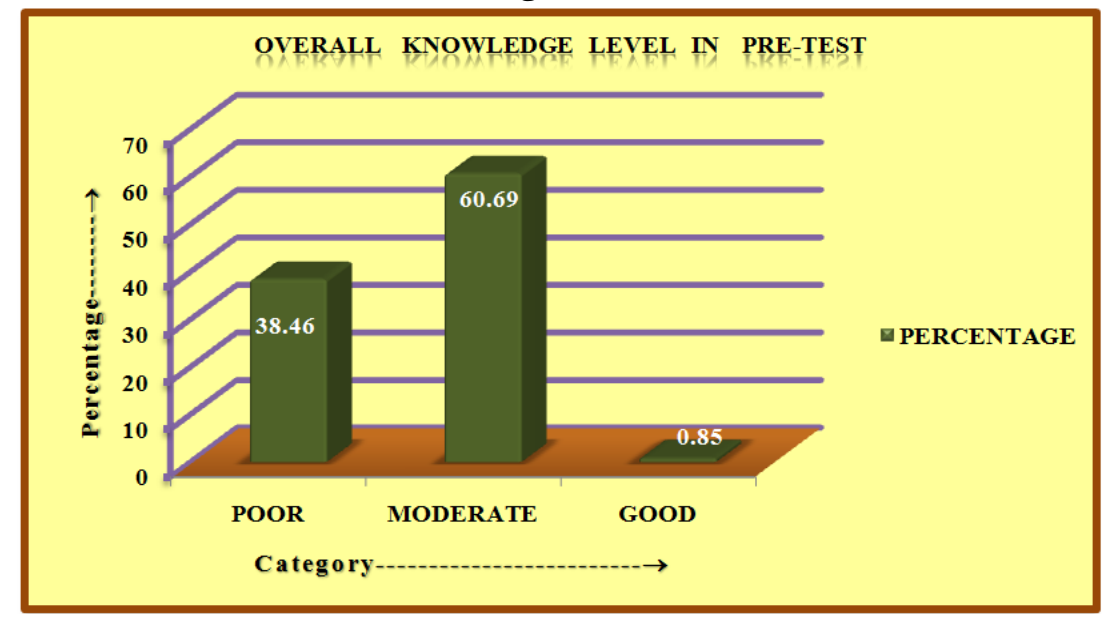

Above table and column chart depicts $38.46 \%$ of respondents were having poor/inadequate knowledge, $60.69 \%$ were having moderate adequate knowledge and $0.85 \%$ were having good/adequate knowledge.

Table: 6: Overall Distribution of Respondent To Knowledge Level In Post-Test

\begin{tabular}{|l|c|c|}
\hline \multicolumn{1}{|c|}{ SCORE } & FREQUENCY & KNOWLEDGE \\
\hline Poor & 20 & 17.09 \\
\hline Average & 39 & 33.34 \\
\hline Good & 58 & 49.57 \\
\hline
\end{tabular}

Figure: 6

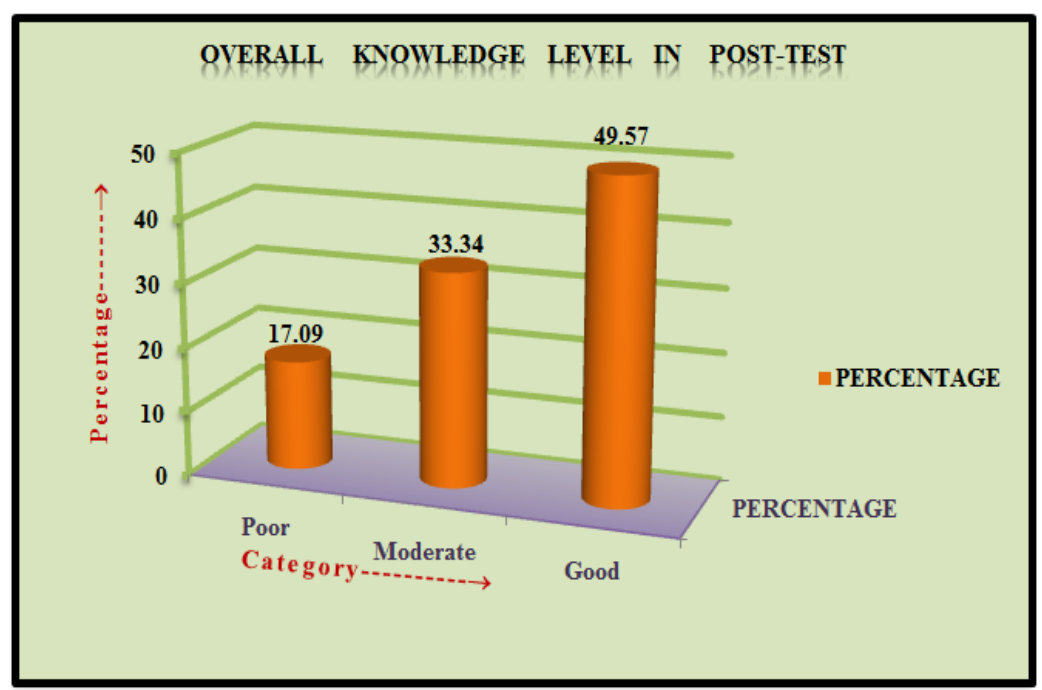

Above table and column chart depicts $17.09 \%$ of respondents were having poor/inadequate knowledge, $33.34 \%$ were having moderate adequate knowledge and $49.57 \%$ were having good/adequate knowledge. 


\section{Section II: Assessment of Practice Score In Both Experimental And Control Group For Both The Pre} And Post Test

Table: 7: Assessment of Practice Regarding Essential Newborn Care Pre-Test Experimental Group

\begin{tabular}{|c|c|c|c|c|}
\hline & Max. Score & Mean & SD & Mean\% \\
\hline PRACTICE & 10 & 4.08 & 0.77 & 40.80 \\
\hline
\end{tabular}

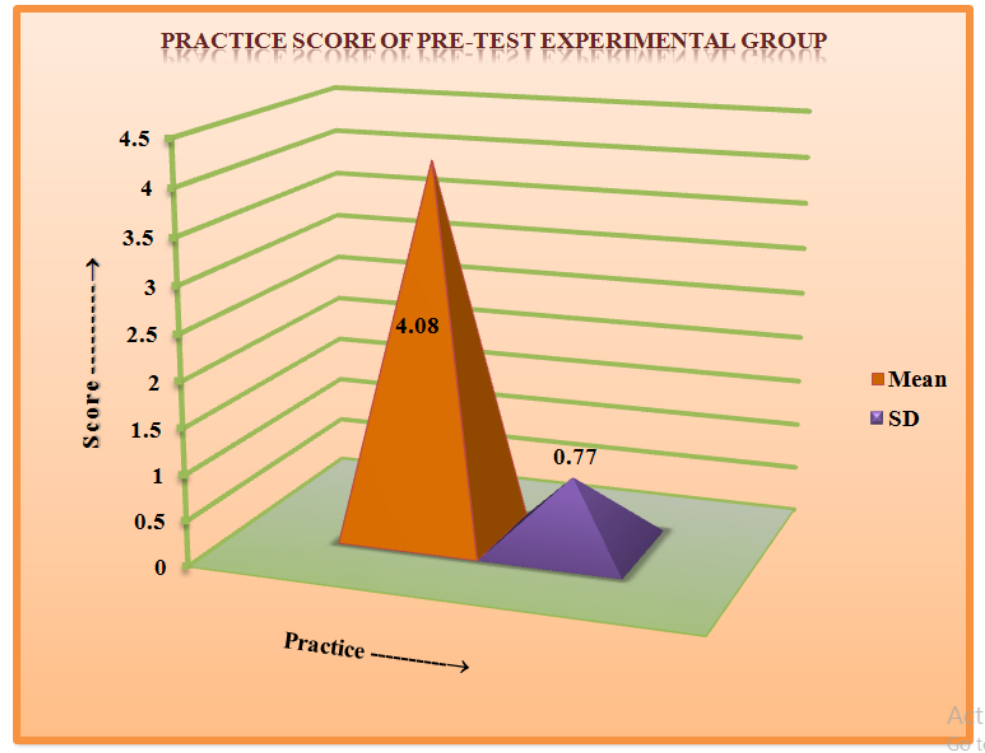

Figure: 7

Above table and column chart illustrates that practice score in experimental group was found to have a mean of 4.08 , SD of 0.77 and mean $\%$ is $40.80 \%$.

Table: 8 Assessment of Practice Regarding Essential Newborn Care Post-Test Experimental Group

\begin{tabular}{|c|c|c|c|c|}
\hline & Max. Score & Mean & SD & Mean\% \\
\hline PRACTICE & 10 & 7.66 & 0.30 & 76.61 \\
\hline
\end{tabular}

Figure: 8

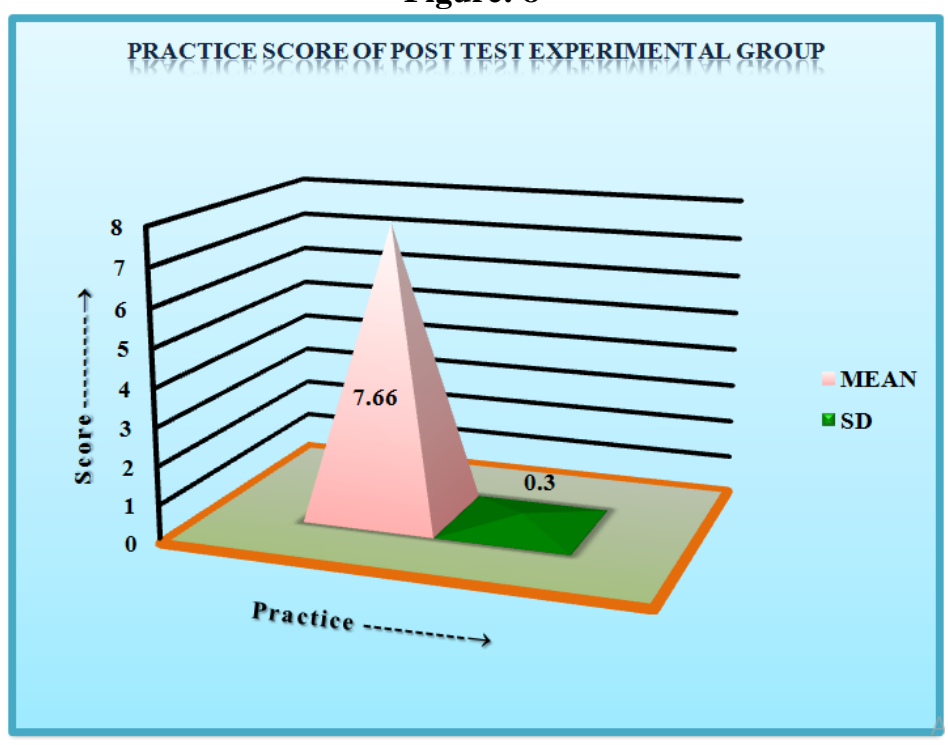


Above table and figure illustrates that practice score of experimental group was found to have a mean of 7.66, SD of 0.30 and mean\% is $76.61 \%$.

Table: 9 Assessment of Practice Regarding Essential Newborn Care Pre-Test Control Group

\begin{tabular}{|c|c|c|c|c|}
\hline & Max. Score & Mean & SD & Mean\% \\
\hline PRACTICE & 10 & 4.41 & 0.73 & 44.1 \\
\hline
\end{tabular}

Figure: 9

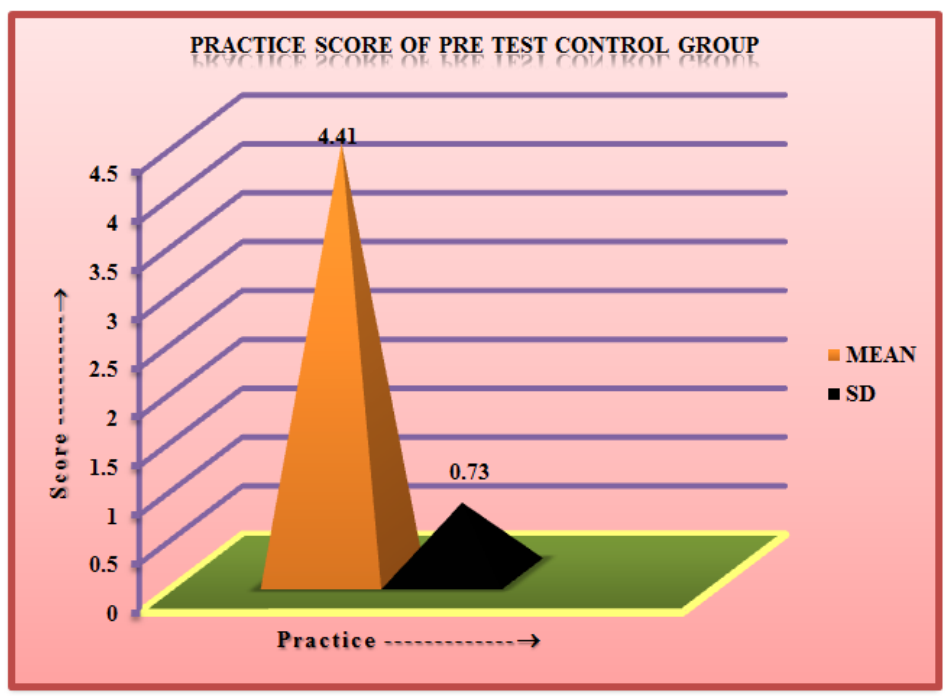

Above table and column chart illustrates that practice score in control group was found to have a mean of 4.41 , SD of 0.73 and mean $\%$ is $44.1 \%$.

Table: 10 Assessment of Practice Regarding Essential Newborn Care Post-Test Control Group

\begin{tabular}{|c|c|c|c|c|}
\hline & Max. Score & Mean & SD & Mean\% \\
\hline PRACTICE & 10 & 4.56 & 0.71 & 45.68 \\
\hline
\end{tabular}

Figure: 10

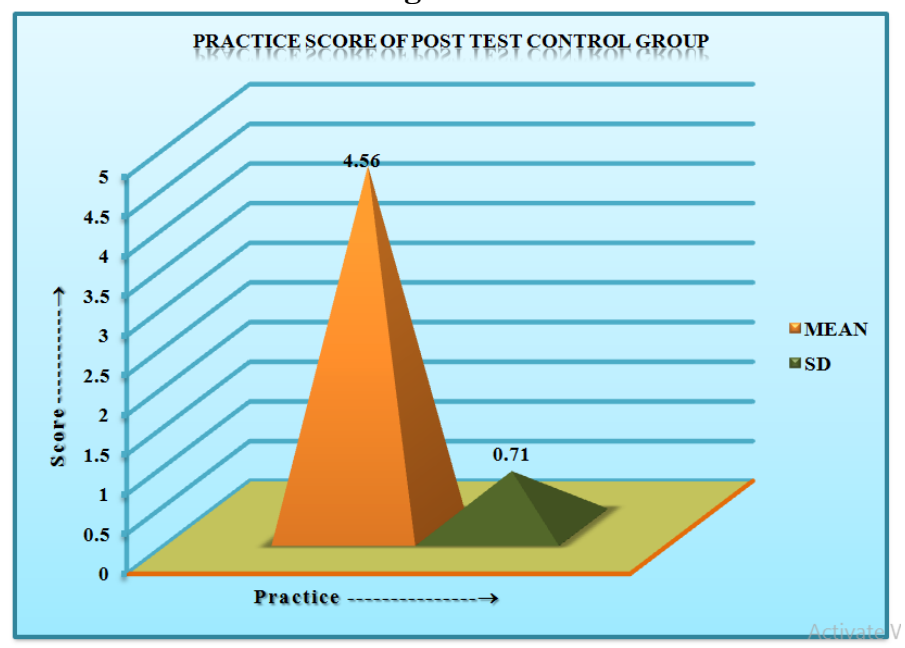

Above table and figure illustrates that practice score in control group was found to have a mean of 4.56, SD of 0.71 and mean\% is $45.68 \%$. 
Table: 11 Overall Distribution of Respondents To Practice In Pre-Test

\begin{tabular}{|l|c|c|}
\hline \multirow{2}{*}{ SCORE } & \multicolumn{2}{|c|}{ PRACTICE } \\
\cline { 2 - 3 } & FREQUENCY & \% \\
\hline Poor Practice & 36 & 30.76 \\
\hline Moderate Practice & 71 & 60.69 \\
\hline Good Practice & 10 & 8.55 \\
\hline
\end{tabular}

Figure: 11

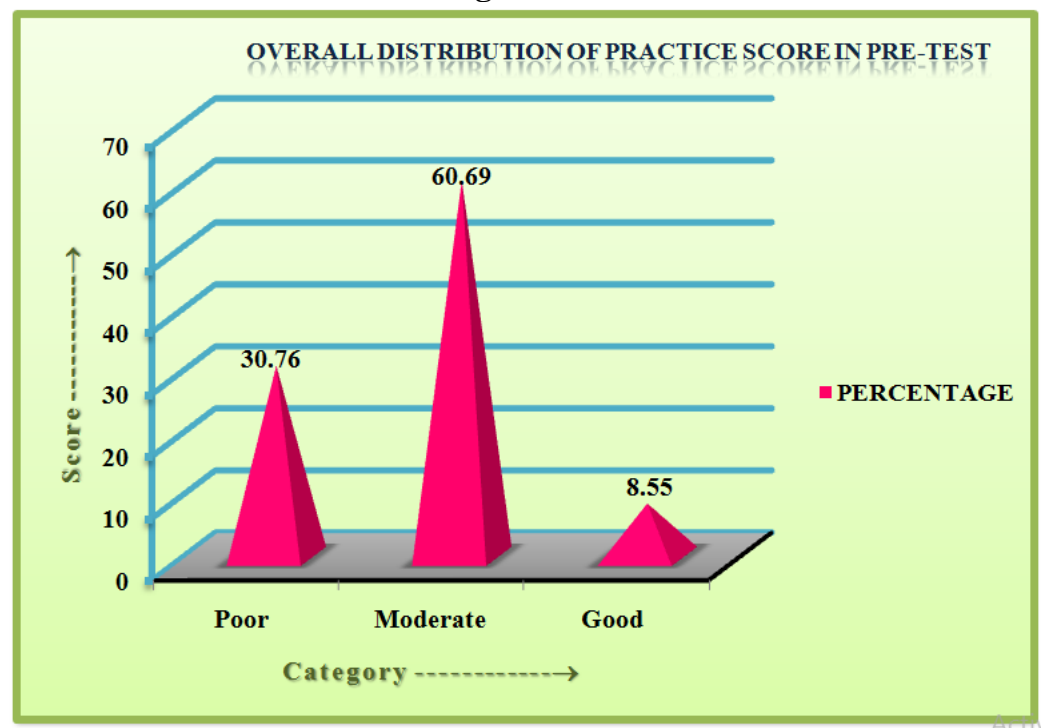

Above table and column diagram depicts that $30.76 \%$ of the sample are having poor practice, $60.69 \%$ moderate practice and $8.55 \%$ are performing good practice in providing essential newborn care.

Table: 12 Overall Distribution of Respondents To Practice In Post-Test

\begin{tabular}{|l|c|c|}
\hline \multirow{2}{*}{ SCORE } & \multicolumn{2}{|c|}{ PRACTICE } \\
\cline { 2 - 3 } & FREQUENCY & 11.11 \\
\hline Poor Practice & 13 & 38.46 \\
\hline Moderate Practice & 45 & 50.43 \\
\hline Good Practice & 59 & \% \\
\hline
\end{tabular}

Figure: 12

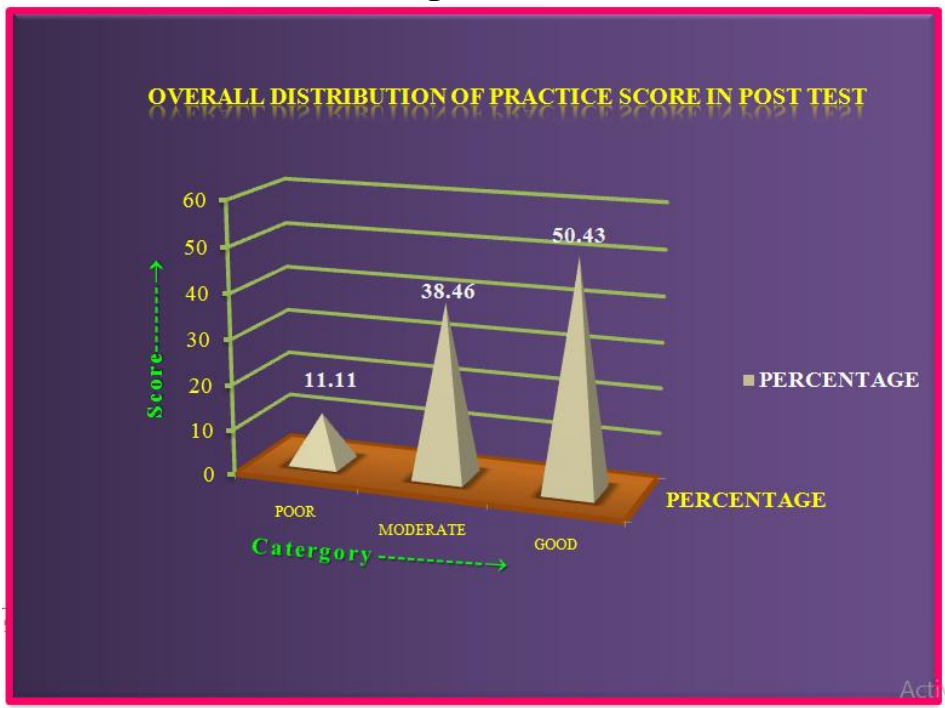

Above table and diagram depicts that $11.11 \%$ performed poor practice, $38.46 \%$ did moderate practice and $50.43 \%$ are performing good practice in providing essential newborn care. 


\section{SECTION III: Effectiveness Of Administering Planned Revised Sop On Enc In The Experimental Group}

$$
\text { Unpaired t-test }=\frac{\overline{\mathrm{X}}_{1}-\overline{\mathrm{X}}_{2}}{\sqrt{\frac{S D_{1}^{2}}{n_{1}}+\frac{S D_{2}^{2}}{n_{2}}}}
$$

$\mathbf{X}_{1}=$ Post test knowledge score of control group with $\mathrm{n}_{1}=58$

$\mathbf{X}_{2}=$ Post test knowledge score of experimental group with $\mathrm{n}_{2}=59$

$\overline{X_{1}}=\frac{\Sigma X_{1}}{n_{1}}=25.76$

$\overline{X_{2}}=\frac{\Sigma \mathbf{X}_{2}}{n_{2}}=11.72$

$\mathrm{SD}=\sqrt{\frac{\Sigma\left(X-\bar{X}^{2}\right.}{n}}$

$\therefore \mathbf{S D}_{1}=16.40 ; \mathbf{S D}_{2}=13.27$

Unpaired t-test score $=\mathbf{5 . 1 0}$

$d f=n_{1}+n_{2}-2=7$

Level of significance $=95 \%(0.05)$

Thus, at $d f=115$ and significance level 0.05 the obtained $p$ value $=5.10$ is found to be more than the table value (1.658) which suggest the significant difference between experimental and control post-test knowledge score.

\section{EFFECTIVENESS OF THE PRACTICE LEVEL IN THE POST-TEST SCORE}

$$
\text { Unpaired t-test }=\frac{\overline{\mathrm{X}}_{1}-\overline{\mathrm{X}}_{2}}{\sqrt{\frac{S D_{1}^{2}}{n_{1}}+\frac{S D_{2}^{2}}{n_{2}}}}
$$

$\mathbf{X}_{1}=$ Post test knowledge score of experimental group with $\mathrm{n}_{1}=59$

$\mathbf{X}_{2}=$ Post test knowledge score of control group with $\mathrm{n}_{2}=58$

$\overline{X_{1}}=\frac{\Sigma \mathrm{X}_{1}}{n_{1}}=7.66$

$\overline{X_{2}}=\frac{\Sigma \mathbf{X}_{2}}{n_{2}}=4.56$

$\mathbf{S D}=\sqrt{\frac{\Sigma(X-\bar{X})^{2}}{n}}$

$\therefore \mathbf{S D}_{1}=6.39 ; \mathbf{S D}_{2}=9.50$

Unpaired t-test score $=\mathbf{2 . 0 8}$

$$
d f=n_{1}+n_{2}-2=115
$$

Level of significance $=95 \%(0.05)$

Thus, at $d f=7$ and significance level 0.05 the obtained $p$ value $=2.08$ is found to be more than the table value (1.658) which suggest the significant difference between experimental and control post-test practice score.

Thus, here the $\mathrm{H}_{1}$ is tested and as the above analysis reveals that there is a significant difference between the pre and post test score of knowledge and practice in the experimental group $\mathbf{H}_{\mathbf{1}}$ is accepted.

Table: 13 Effectiveness of Administering Planned Revised Sop On Enc Difference Between The Pre And Post Test Score of Experimental Group

\begin{tabular}{|c|c|c|}
\hline & KNOWLEDGE & PRACTICE \\
\hline PRE-TEST SCORE & 653 & 241 \\
\hline POST-TEST SCORE & 1520 & 452 \\
\hline DIFFERENCE & 867 & 211 \\
\hline
\end{tabular}


Figure: 13

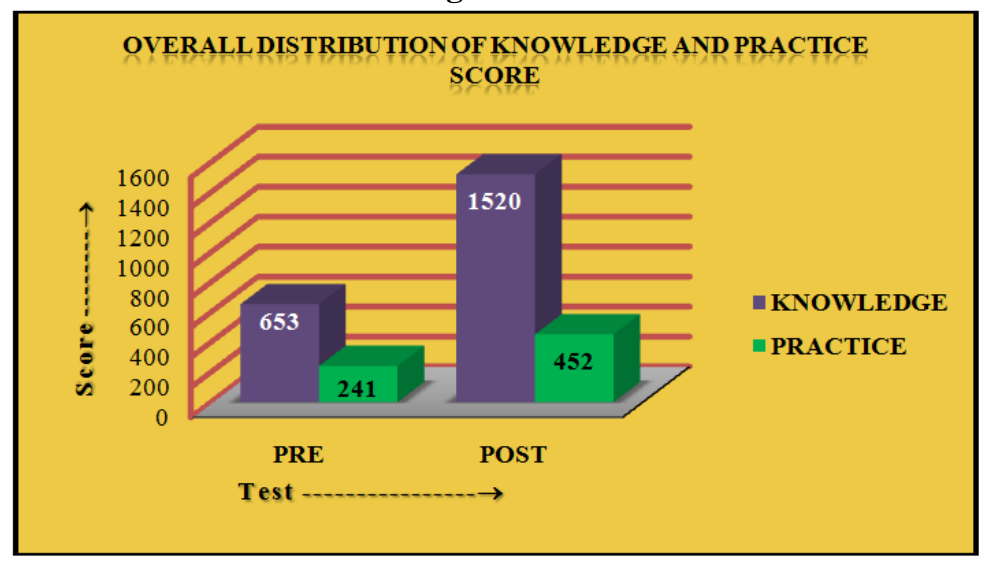

Above table and diagram depicts the significant difference between the pre and post test score of knowledge and practice level of the respondents under the experimental group.

Table: 14 Distribution of Mean Percentage And "t" - Value of Post Test Knowledge Score In Experimental And Control Group

\begin{tabular}{|c|c|c|c|}
\hline $\begin{array}{c}\text { POST-TEST } \\
\text { KNOWLEDGE }\end{array}$ & MEAN \% & $\begin{array}{c}\text { MEAN } \\
\text { DIFFERENCE }\end{array}$ & t -VALUE \\
\hline Experimental & 85.86 & 46.78 & $5.10^{*}$ \\
\hline Control & 39.08 & & \\
\hline
\end{tabular}

$* \mathrm{t}(0.05,115)=1.658$

Figure: 14

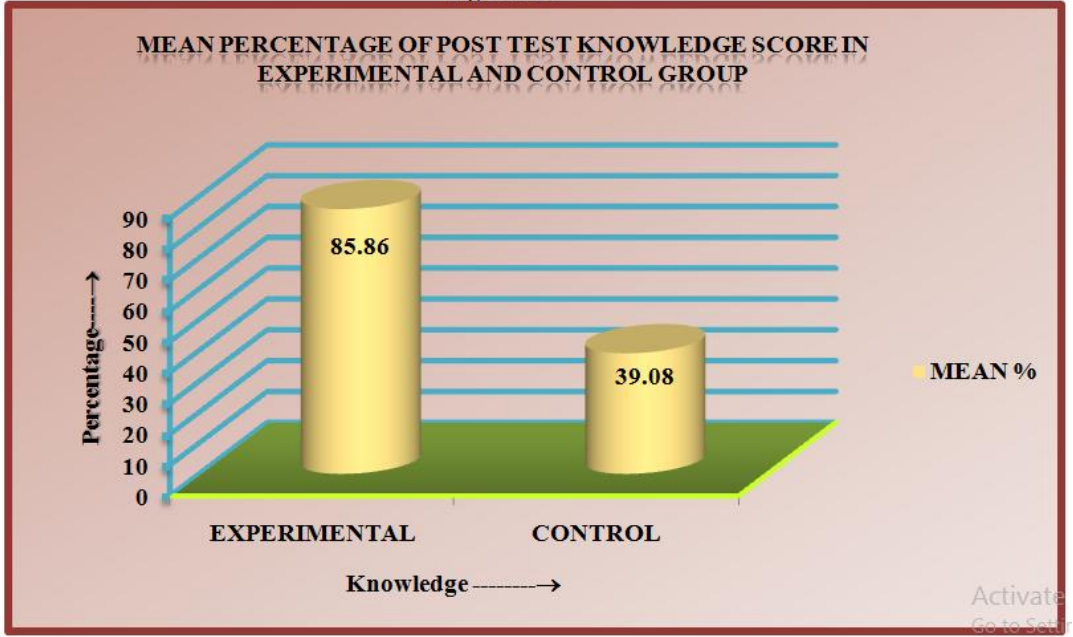

Above column diagram reveals the mean percentage of post test knowledge score in experimental is $85.86 \%$ and in control group is $39.08 \%$

Table: 15 Distribution of Mean Percentage And “t” - Value of Post Test Knowledge Score In Experimental And Control Group

\begin{tabular}{|c|c|c|c|}
\hline POST-TEST PRACTICE & MEAN \% & $\begin{array}{c}\text { MEAN } \\
\text { DIFFERENCE }\end{array}$ & t -VALUE \\
\hline Experimental & 76.61 & 30.93 & $2.08^{*}$ \\
\hline Control & 45.68 & & \\
\hline
\end{tabular}

$* \mathrm{t}=(0.05,115)=1.658$ 
Figure: 15

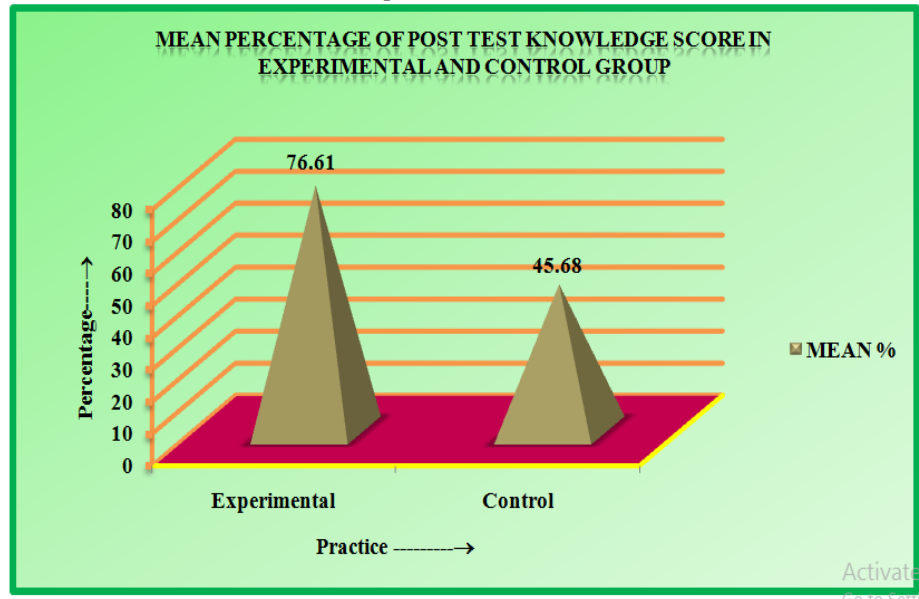

Above column diagram reveals the mean percentage of post test practice score in experimental is $76.61 \%$ and in control group is 45.68

\section{SECTION IV: Correlation between the knowledge and practice regarding revised standard operative procedure on essential newborn care}

$\mathbf{X}=$ Pre-test knowledge score of both experimental and control group

$\mathbf{Y}=$ Pre-test practice score of both experimental and control group

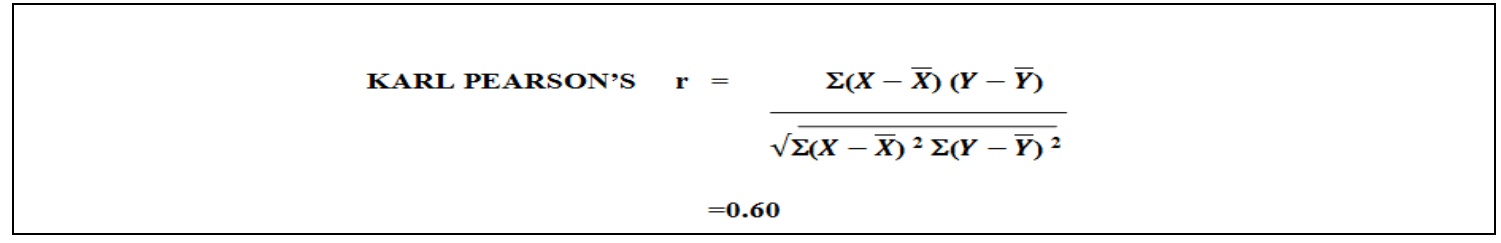

The correlation co-efficient value(r) obtained by using Karl Pearson's correlation co-efficient is 0.60 so there exists a positive correlation between the knowledge and practice.

\section{Conclusion}

The teaching session and the simulated training regarding revised standard operative procedure were effective as there is a significant difference in the pre-test and post-test knowledge and practice score among the experimental group.

\section{Conflict Of Interest}

Confidentiality of data sources was maintained by obtaining prior consent from the study subjects before starting the study for their willing participation in this research.

Source of Funding

Researcher's own funding was used to conduct this study

\section{Ethical Clearance}

University Ethical Committee has approved the research and provided ethical clearance certificate to proceed with the research

\section{References}

[1] Abbas K.A(1995). A study of two and half year admissions in neonatal unit of children's Hospital, Larkana, Pak Paediatric J; 19:2932

[2] Costello A and Manandhar D (ed.) (2000). Improving Newborn Infant health in developing Countries. Available at ttp://www.wspc.com.sg/ books/medscip083.htm

[3] Essential Newborn Care: Report of a Technical Working Group (Trieste, Italy, 25-29April 1994).WHO Geneva, 1994.

[4] Olyweni D, Amado Y, N damugoba A. Best Practice In newborn Healthcare [Internet]. vsointernational.org. 2015 [cited 16 March 2016]. Available from: https://www.vsointernational.org/sites/vso_international/files/vso_best_practice_in_newborn_healthcare.pdf

[5] Standard Operating Procedures ,Clinical Research Resource HUB [Internet]. Hub.ucsf.edu. 2016 [cited 27 March 2016 ]. Available from: https://hub.ucsf.edu/sops

[6] Marsh, D., Darmstadt, G., Moore, J., Daly, P., Oot, D., \& Tinker, A., (2002). Advancing newborn health and survival in developing countries: A conceptual framework. J Perinatol 2002;22 :572-576. 